\title{
Indicadores sanguíneos hematológicos e hormonais do estresse na avicultura
}

\author{
Blood hematological and hormonal indicators of stress in poultry \\ Indicadores hematologicos y hormonales de estrés en aves de corral
}

Recebido: 29/01/2022 | Revisado: 02/02/2022 | Aceito: 11/02/2022 | Publicado: 16/02/2022

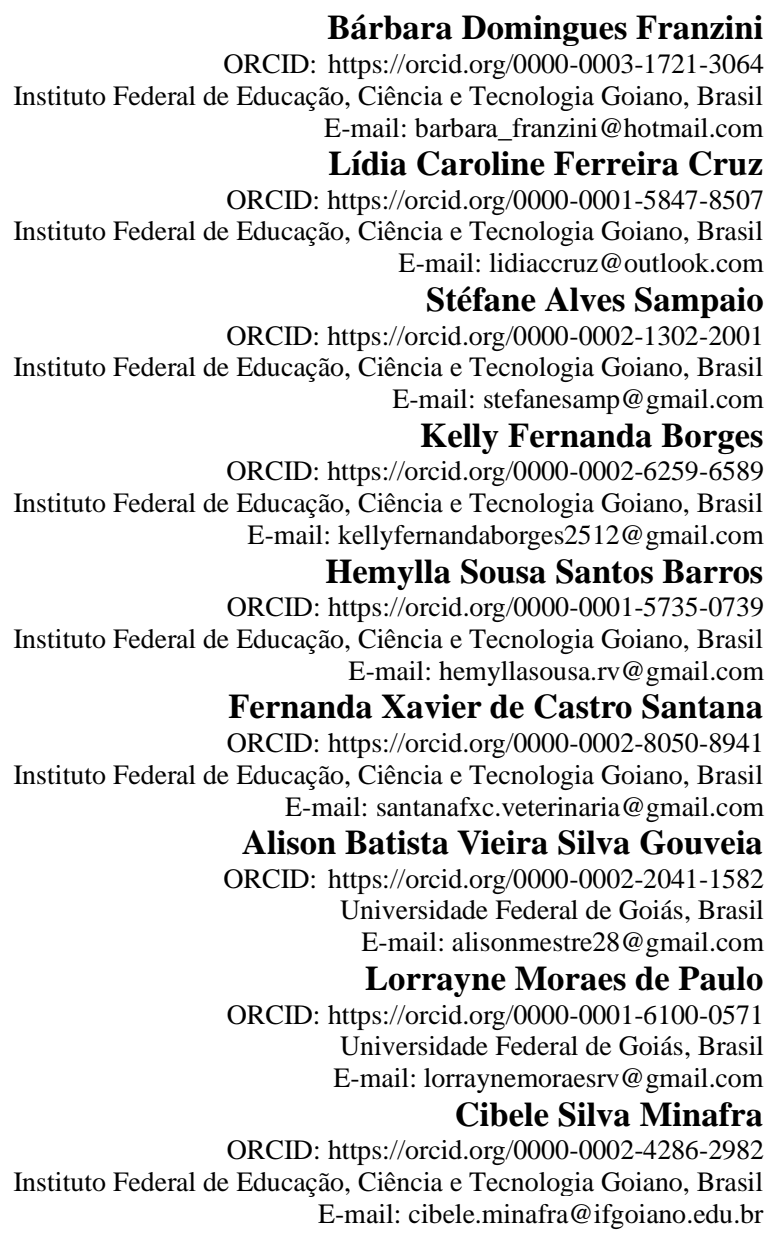

\section{Resumo}

Com o crescente avanço da avicultura, problemas com o manejo e alterações metabólicas nas aves, começaram a aparecer nas granjas, destacando-se o estresse calórico. Por se tratar de um país de clima tropical, a diversidade de temperatura mostra-se um importante fator estressante a ser considerado pelos produtores. Além do estresse térmico, vários fatores estressores merecem atenção dos produtores, principalmente no manejo pré-abate das aves. Técnicas de captura, melhoria no transporte e planejamento no tempo de espera pré-abate fazem-se necessárias para o melhor bem-estar animal, resultando em melhor produto ofertado ao consumidor. Quando os animais são submetidos a condições adversas, são desencadeados mecanismos de estímulo hormonal e hematológicos com a intenção de preparar e disponibilizar os recursos necessários para o organismo enfrentar as demandas emergenciais compensatórias, visando à manutenção do seu equilíbrio. Objetiva-se com esta revisão de literatura relatar as principais alterações que ocorrem nas células hematológicas e hormônios plasmáticos durante o estresse na produção avícola, relatando as perspectivas futuras dessas análises.

Palavras-chave: Avicultura; Eritrócitos; Leucócitos; Sistema endócrino; Tiroxina.

\section{Abstract}

With the increasing advancement of poultry, problems with management and metabolic changes in birds began to appear on farms, especially heat stress. As it is a country with a tropical climate, temperature diversity is an important stressor to be considered by producers. In addition to thermal stress, several stressors deserve attention from producers, especially in the pre-slaughter management of birds. Capture techniques, improved transport and pre- 
slaughter waiting time planning are necessary for the best animal welfare, resulting in a better product offered to the consumer. When animals are subjected to adverse conditions, hormonal and hematological stimulation mechanisms are triggered with the intention of preparing and providing the necessary resources for the organism to face the compensatory emergency demands, aiming to maintain its balance. The objective of this literature review is to report the main changes that occur in hematological cells and plasma hormones during stress in poultry production, reporting the future perspectives of these analyses.

Keywords: Endocrine system; Erythrocytes; Leukocytes; Poltry; Thyroxine.

\section{Resumen}

Con el avance cada vez mayor de las aves de corral, comenzaron a aparecer en las granjas problemas con el manejo y los cambios metabólicos en las aves, especialmente el estrés por calor. Al ser un país con clima tropical, la diversidad de temperatura es un estresor importante a considerar por los productores. Además del estrés térmico, varios factores estresantes merecen la atención de los productores, especialmente en el manejo previo al sacrificio de las aves. Las técnicas de captura, el transporte mejorado y la planificación del tiempo de espera previo al sacrificio son necesarios para el mejor bienestar animal, lo que se traduce en un mejor producto ofrecido al consumidor. Cuando los animales son sometidos a condiciones adversas, se activan mecanismos de estimulación hormonal y hematológica con la intención de preparar y proporcionar los recursos necesarios para que el organismo enfrente las demandas compensatorias de la emergencia, visando mantener su equilibrio. El objetivo de esta revisión bibliográfica es reportar los principales cambios que ocurren en las células hematológicas y hormonas plasmáticas durante el estrés en la producción avícola, reportando las perspectivas futuras de estos análisis.

Palabras clave: Aves de corral; Eritrocitos; Leucocitos; Sistema endocrino, Tiroxina.

\section{Introdução}

A avicultura é uma atividade em crescente expansão em diversos países. No Brasil, ela é responsável por, aproximadamente, $1,5 \%$ do PIB nacional e pela geração de quase 5 milhões de empregos diretos e indiretos, na produção e na indústria, gerando mais de R $\$ 6$ bilhões em impostos (ABPA, 2021). A evolução científica e tecnológica atual permite que os profissionais da ambiência animal possam priorizar o desenvolvimento sustentável em toda a cadeia de produção de proteína animal, com o intuito de reduzir perdas produtivas ao longo de todo o processo produtivo. O estudo da ambiência animal com ênfase no conforto térmico nos diversos ambientes de produção e bem-estar dos animais nas diferentes instalações e sistemas produtivos está cada vez mais atuante (Silva \& Vieira, 2010).

O Brasil devido ao seu clima tropical possui temperaturas elevadas durante o ano em grande parte de seu território. Porém, para a avicultura, esse clima não é adequado devido à sensibilidade a altas temperaturas, gerando diminuição do desempenho dos frangos de corte e menor bem-estar, ocorrendo assim um prejuízo ao produtor (Navas et al., 2016). A alta temperatura ambiente desencadeia alterações fisiológicas e comportamentais, resultando em diminuição da taxa de crescimento, no consumo e utilização de ração pelas aves, aumento da ingestão de água, taquicardia, taquipneia, imunossupressão e alterações hematológicas (El-Kholy et al., 2017). Essas alterações aumentam a conversão alimentar, reduzem o ganho de peso, a qualidade e o número dos ovos e comprometem a qualidade da carcaça, além de aumento na taxa de mortalidade, gerando altos prejuízos econômicos para o setor avícola (Porto e Fontenele-Neto et al., 2017).

Além do estresse térmico, outros fatores incluem para um processo multifatorial e extremamente estressante, como o transporte até o matadouro. As aves podem ser expostas a muitos estressores potenciais, incluindo movimento, vibração, aceleração, luz do dia, ruído desconhecido, confinamento, superlotação, privação de comida e água além de temperaturas extremas. As consequências do estresse nas aves são mudanças de comportamento; alterações nos parâmetros fisiológicos, alterações hematológicas, enzimáticas e hormonais; e outras alterações patológicas, tais como alterações da glândula adrenal, ossos e músculos (Vosmerova et al., 2010).

Estresse é um termo utilizado quando há respostas fisiológicas desencadeadas pelo organismo animal diante de condições adversas para manutenção da homeostase. Tais respostas podem ser representadas por alterações do ritmo cardiorrespiratório, temperatura corporal e secreção hormonal, acarretando mudanças no comportamento e no desempenho do animal, a fim de aumentar as chances de sobrevivência do indivíduo (Carrasco \& Van de Kar, 2003). 
Os efeitos do estresse térmico se agravam com a retirada prolongada de alimentos ou de água e por exposição a vibrações e acelerações no transporte (Mitchell \& Kettlewell, 2009). Alterações como leucocitose com heterofilia devido à liberação de hormônios adrenais, ou até mesmo monocitose em algumas espécies, são alguns parâmetros hematológicos notados após períodos de estresse em aves. Na parte bioquímica e hormonal, há alterações como aumento da osmolalidade plasmática diante da privação hídrica (Cândido, 2008). No estresse por calor, há mais liberação de glicocorticoides pelo hipotálamo, levando a aumentos no índice glicêmico, com inibição da síntese de ácidos graxos pelo fígado gerando um efeito catabólico, com consequente perda de peso e baixo crescimento da ave. Há também a diminuição da liberação de hormônios pela hipófise, tais como hormônio de crescimento (GH) e hormônio tireotrófico (TSH), contribuindo ainda mais com o efeito catabólico (Navas et al., 2018).

Diante o exposto objetivou-se com essa revisão abordar os indicadores hematológicos e hormonais diante o estresse por calor e no manejo pré abate na avicultura, um problema bastante comum nas granjas avícolas brasileiras.

\section{Metodologia}

O presente estudo apresentou-se como descritivo (Prodanov \& Freitas, 2013), sendo realizada pesquisa bibliográfica do tipo narrativa (Zambello et al, 2018) acerca dos indicadores sanguíneos hematológicos e hormonais do estresse na avicultura.

$\mathrm{Na}$ elaboração do presente estudo a abordagem metodológica utilizada foi revisão exploratória, de natureza qualitativa, por meio de pesquisa bibliográfica sobre "Indicadores sanguíneos hematológicos e hormonais do estresse na avicultura". Os artigos utilizados para a confecção desta revisão foram retirados de bases indexados: CAPES, PUBMED, SCIELO, SCOPUS, SCIENCE DIRECT, ELSEVIER, sendo recorte temporal das últimas duas décadas. As palavras chaves de pesquisa utilizadas foram: hematology and chickens/broilers; immune system and broilers/chicken/poltry; hormones and broilers/chicken/poltry, priorizando os artigos mais recentes sobre $\mathrm{o}$ assunto.

\section{Efeitos do Estresse por Calor na Avicultura}

A fase final da produção pode sofrer perdas produtivas e econômicas, devido à alta sensibilidade às alterações térmicas das aves, com redução dos índices zootécnicos e aumento da mortalidade. Altas temperaturas no ambiente reduz a capacidade da ave em dissipar calor gerando desequilíbrio ácido base, denominado alcalose respiratória (Brossi et al., 2009). A condição térmica do ambiente do alojamento é a combinação dos efeitos da temperatura do ar, da umidade relativa, da radiação solar incidente e da velocidade do ar a que a ave está submetida. A produtividade ideal da ave depende da qualidade dessa condição nos locais em que as mesmas estão inseridas (Garcia et al., 2012).

A manutenção da homeotermia é eficiente em temperatura ambiental na zona de termoneutralidade. Variações nos extremos dessa zona ameaçam a vida das aves e, portanto, é importante que o alojamento garanta o balanço térmico (Silva et al., 2012).

A faixa de termoneutralidade é a zona de conforto térmico definido como a faixa de temperatura ambiente em que a taxa metabólica é mínima e a homeotermia é mantida com menos gasto energético. Quando a temperatura ambiente é maior que a temperatura de conforto, a ave diminui o consumo de alimento e gasta mais energia para dissipar calor e manter a homeotermia, piorando o desempenho das aves (Macari \& Furlan, 2002). A Figura 1 abaixo apresenta a zona termoneutra das aves, enquanto a Tabela 1 relaciona a temperatura ambiente ideal para cada semana de vida do frango de corte: 
Figura 1: Zona termoneutra de aves.

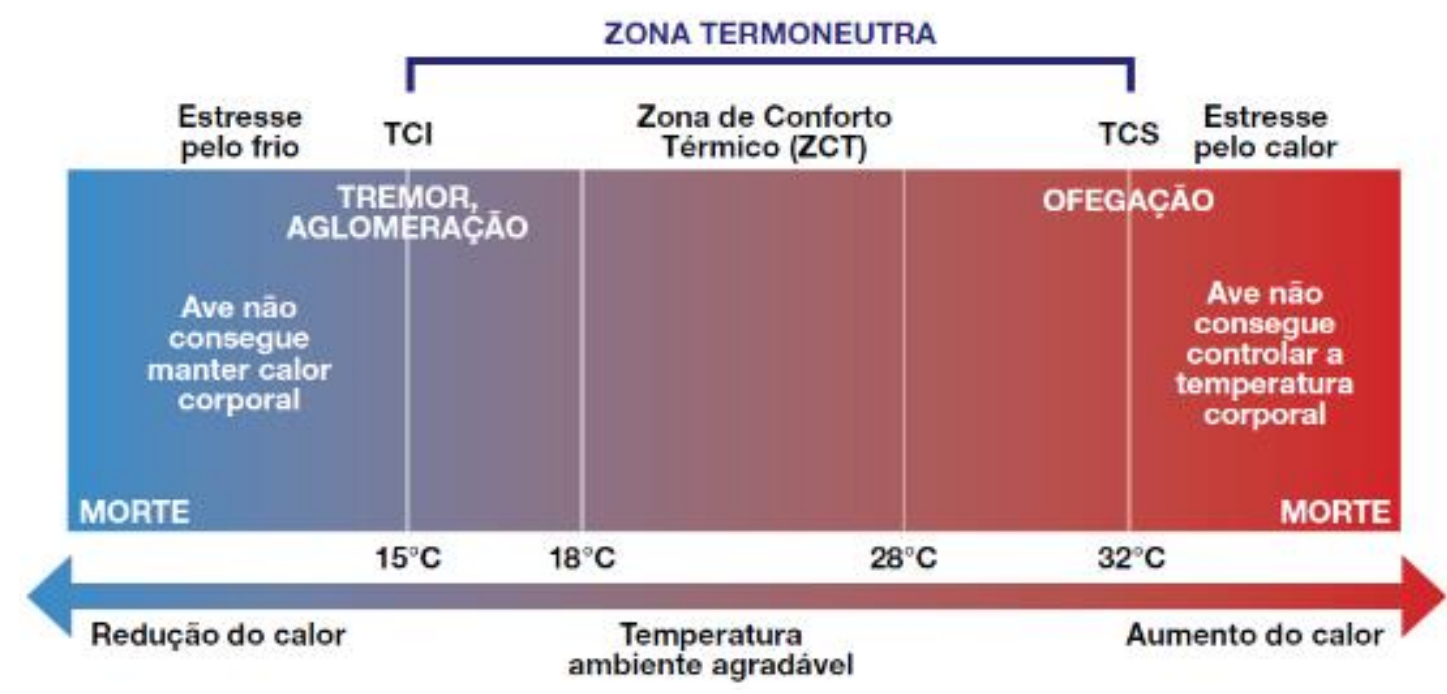

Fonte: Ludke et al. (2010)

Tabela 1: Média de temperatura ambiente por semana para frangos de corte.

\begin{tabular}{cc}
\hline Idade (semanas) & Temperatura Ambiente $\left({ }^{\circ} \mathrm{C}\right)$ \\
\hline 1 & $32-35$ \\
3 & $29-32$ \\
4 & $26-29$ \\
5 & $23-26$ \\
6 & $20-23$ \\
7 & 20 \\
\hline
\end{tabular}

Fonte: Abreu e Abreu (2011).

O conforto térmico era considerado um problema secundário dentro da produção de frangos de corte, ficando em segundo plano, quando comparado aos aspectos de sanidade, genética e nutrição. Porém à medida que a tecnologia avançou e os níveis de confinamento também, a ambiência tornou-se um assunto extremamente importante, principalmente, no que diz respeito à redução dos índices de perdas durante o processo produtivo e as exigências quanto o bem-estar animal e boas práticas de manejo (Barbosa Filho, 2008).

As aves são animais homeotermos, que dispõem de um centro termorregulador, localizado no hipotálamo capaz de controlar a temperatura corporal através de mecanismos fisiológicos e respostas comportamentais, mediante a produção e liberação de calor, mecanismos que regulam a manutenção da temperatura corporal normal. Quando expostas ao calor, respostas fisiológicas compensatórias como vasodilatação periférica aumenta a perda de calor não evaporativo. Para aumentar a dissipação do calor, a ave consegue aumentar a área superficial ao manter as asas afastadas do corpo, eriçando as penas e intensificando a circulação periférica (Figura 2). A perda de calor não evaporativo pode também ocorrer com o aumento da produção de urina, se esta perda de água for compensada pelo maior consumo de água fria (Borges et al., 2003). 
Figura 2:Principais mecanismos de dissipação do calor utilizado pelas aves de produção quando em estresse por calor.

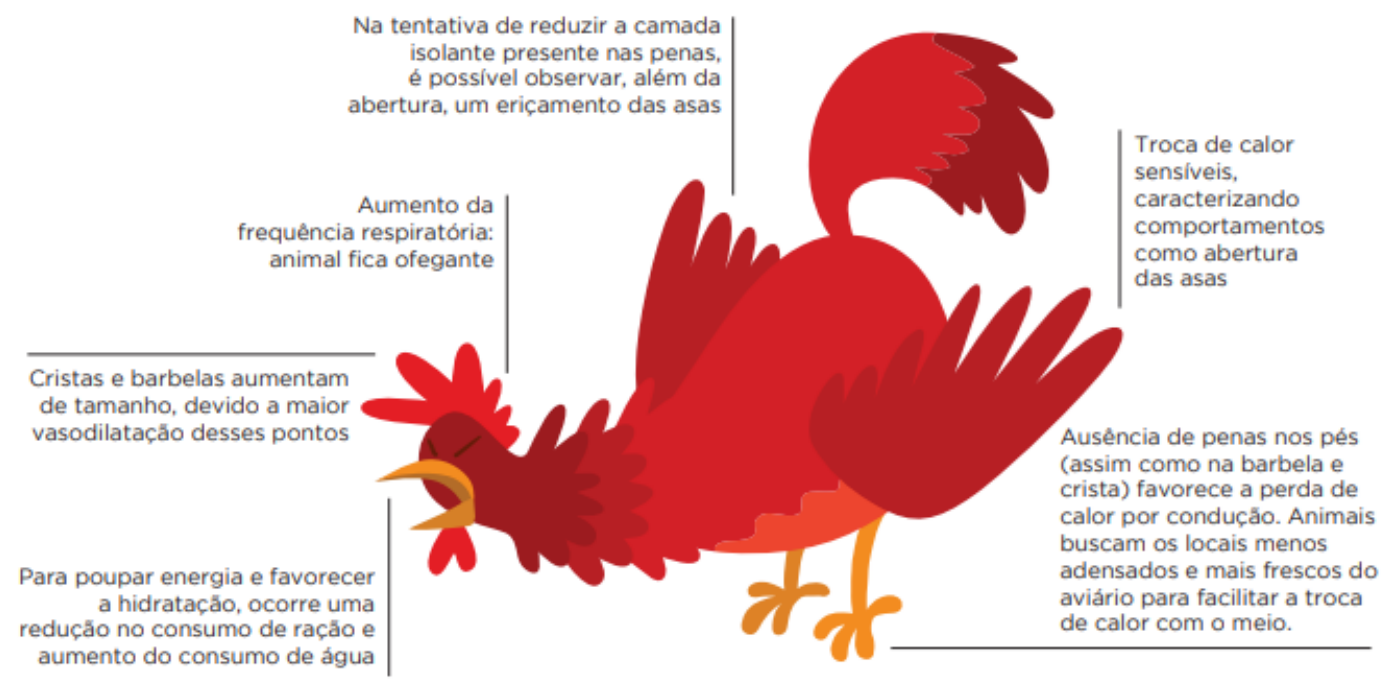

Fonte: Gobi (2020)

Além disso, aves não possuem glândulas sudoríparas, o que também dificulta o processo de troca de calor. Possuem o corpo recoberto por penas para manter sua temperatura corporal em equilíbrio. A troca de calor com o ambiente ocorre pelo aumento da frequência respiratória, aumentando a eliminação do CO2 e diminui a disponibilidade de bicarbonatos (HCO3) utilizados na formação da casca do ovo, e, portanto, comprometendo a formação da mesma (Albino et al., 2014). O comprometimento da mineralização e qualidade da casca do ovo se fazem devido ao aumento da frequência respiratória, pois há o aumento do pH, em função da alcalose respiratória, reduzindo a quantidade de cálcio no sangue (Ebeid et al., 2012).

A tolerância ao calor é um critério não muito explorado no campo do melhoramento genético (Duangjinda et al., 2017).

Exposição a altas temperaturas causa redução na ingestão de alimentos, prejudica a taxa de crescimento, o rendimento de carcaça e qualidade da carne, além de aumentar o gasto energético para tentar dissipar o calor excedente, ocasionando um menor ganho de peso (Navas et al., 2016). Provocam diversas mudanças na fisiologia neuroendócrina das aves, com ativação contínua do eixo hipotálamo-hipófise-adrenal (HPA), aumentando o catabolismo proteico, hiperglicemia, imunossupressão e aumento da susceptibilidade a infecções devido à elevação de corticosterona circulantes de (Ebrahimzadeh et al., 2012; Mehaisen et al., 2017).

O consumo de alimentos também é regulado pelo hipotálamo e quando influenciado pelo calor, reduz o estimulo sobre a medula da suprarrenal na produção de hormônios responsivos pela manifestação da fome, pois o consumo de alimentos está associado à produção de calor, estimulando a suprarrenal a produzir glicocorticoides que geram hiperglicemia para fins de produção de energia e síntese de ácidos graxos no fígado inibida. Esse efeito catabólico e a gliconeogênese, gera constante degradação de tecidos musculares e gordurosos, assim como a inibição da síntese destes tecidos, provocando a perda de peso e crescimento reduzido (Encarnação, 1992).

Alterações da resposta hipofisária frente ao estresse calórico caracterizam-se como menor secreção de hormônio de crescimento (GH) e hormônio tireotrófico (TSH), conduzindo a uma redução da atividade da tireoide, importante para o crescimento do animal, pois por intermédio de seus hormônios estimula o metabolismo das proteínas, gorduras, carboidratos, água, minerais e energia, além da imprescindível função no crescimento. Os hormônios de crescimento e gonadotróficos têm grande efeito anabólico, estimulando o crescimento e desenvolvimento da musculatura, como também do tecido ósseo e 
adiposo (Encarnação, 1992).

As respostas fisiológicas das aves ao estresse por calor podem ser mais bem representadas esquematicamente na Figura 3.

Figura 3: Respostas fisiológicas das aves ao estresse calórico.

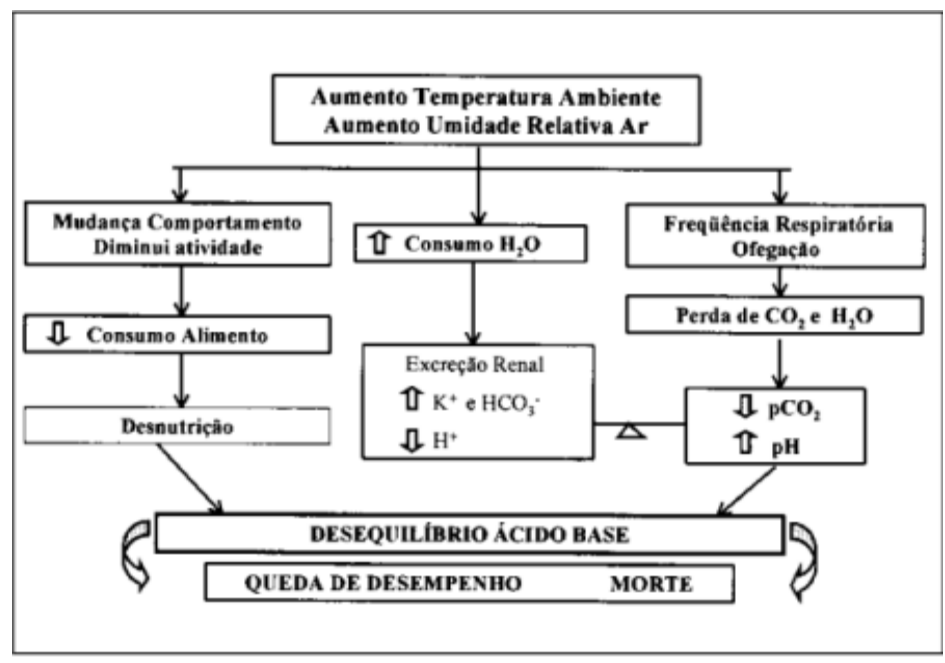

Fonte: Borges (2003)

\section{Efeitos do Estresse no Manejo Pré Abate}

\subsection{Perdas pré abate}

O mercado produtivo de frangos de corte perde todo ano mais de dois milhões de dólares devido às mortes das aves antes da chegada à linha do abate (Vieira et al., 2012). Tais perdas ocorrem em grande parte durante as operações pré-abate. 40 $\%$ das perdas totais são pelo estresse térmico, sendo $10 \%$ devido ao estresse térmico na condição de espera (Vieira, 2008).

A maioria das empresas integradoras acredita que o número de aves mortas é o único indicador que oferece informações importantes sobre as condições oferecidas aos animais durante as etapas pré-abate, mas existem outros indicadores que devem ser usados, como a incidência de ossos quebrados, a qualidade de carne e medidas fisiológicas (Vieira, 2008).

Mais atenção é dada à questão dos cuidados com as operações pré-abate dos animais à medida que as normas e leis em prol do bem-estar avançam. Pesquisas científicas identificam e quantificam os agentes causadores de estresse durante as etapas das operações pré-abate, devido principalmente à quantidade de perdas decorrentes deste processo (Barbosa Filho, 2008). Países desenvolvidos que importam esse produto brasileiro já possuem normas próprias que regulam as operações préabate, como Regulamento do Conselho Europeu (CE) $\mathrm{n}^{\circ} 1 / 2005$ (CEC, 2005). Tais disposições do CE referem-se principalmente ao processo de apanha, carregamento e transporte. As regulamentações referentes às operações de pré-abate fazem parte do Código de Recomendações para o bem-estar dos animais (DEFRA, 2007).

No Brasil, foi criado o Programa Nacional de Abate Humanitário com o intuito de padronizar as operações no préabate e abate dos animais de produção (Sociedade Mundial De Proteção Animal-WSPA, 2017), com o objetivo de resgatar a sensibilidade das pessoas, enfatizando a importância de se evitar o sofrimento nos animais. O termo "abate humanitário" é definido como o conjunto de diretrizes técnicas e científicas que garantam o bem-estar dos animais desde a recepção até a operação de sangria (Brasil, 2000). 


\subsection{Principais pontos críticos do manejo pré-abate}

\subsubsection{Captura}

O manejo de captura (apanha) das aves é uma importante etapa pré-abate, onde as aves estão mais susceptíveis ao estresse, influenciando diretamente o bem-estar e a qualidade da carcaça. As lesões observadas em frangos de corte após um carregamento não apropriado podem evoluir de um simples arranhão na pele a problemas como contusões, fraturas e edemas, depreciando as carcaças e respectivos cortes, gerando prejuízos ao produtor e à agroindústria (Rodrigues et al., 2017).

A apanha diurna aumenta o percentual de risco de contusões, o que pode ser devido à maior atividade aviária em resposta à maior quantidade de luz. Esse risco é diminuído na apanha noturna, pois os níveis de iluminação e temperatura no aviário podem ser controlados (Nijdam et al., 2004). Há dois tipos de apanha: a mecânica e a manual. De acordo com os estudos de Nijdam et al. (2005) os dois métodos de captura revelaram altos níveis de corticosterona no plasma sanguíneo das aves estudadas, indicando que ambos se equivalem na indução de estresse. Concluíram também que a apanha mecânica tende a causar índices superiores de mortalidade. Além disso, o alto custo, as modificações nas instalações dos aviários, no transporte e plataforma inviabilizam o uso da apanha mecânica no Brasil, sendo então a apanha manual a forma mais utilizada (Rui et al., 2011).

De acordo com Rui et al. (2011), há três formas de apanha manual: pelas pernas, método que causa mais lesão na carcaça e menos eficiente; o método do dorso, mais utilizado, pois é a forma mais fácil de introduzir as aves dentro da caixa; e o terceiro método, a captura pelo pescoço, na qual as aves são pegas três em cada mão com a desvantagem de causar arranhões no dorso e coxas ao introduzir as aves nas caixas. Este último também aumenta a chance de mortalidade no transporte, pois a apanha pelo pescoço pode provocar asfixia. Ainda, o protocolo de bem-estar para frangos e perus (UBA, 2008) também recomenda que a apanha das aves pelos pés, asas e pescoço não sejam feitas, pois causam lesões e sofrimentos, salvo algumas exceções. Ressalta ainda que somente é permitida a apanha pelo dorso de no máximo duas aves por vez.

Para evitar comprometimento das aves, é necessário adotar práticas de manejo que objetivam o bem-estar, incluindo técnicas que auxiliam na distribuição uniforme das aves no momento da apanha. A organização e a capacitação das equipes de apanha são manejos que podem amenizar o estresse em aves (Pilecco et al., 2011).

\subsubsection{Transporte}

O transporte define-se como a tarefa de encaminhar as aves do aviário até o abatedouro, podendo ser executada em diferentes condições, distância e tipos de vias. Essas condições refletem diretamente na qualidade do produto final (Barbosa Filho, 2008).

De acordo com Mitchell e Kettlewell (2009) existem inúmeras variáveis que contribuem para o alto índice de mortalidade, tais como: a saúde dos animais, o estresse térmico, as injúrias e traumas ocorridos nas etapas anteriores ao transporte. Cada um desses fatores e suas várias combinações podem impor estresse às aves, mas é bem conhecido que os desafios térmicos e, em particular, o estresse térmico constituem a principal ameaça ao bem-estar e à produtividade dos animais. Tais efeitos tendem a aumentar pela retirada prolongada de alimentos ou de água e por exposição a vibrações e acelerações no trasporte. Estresse térmico é geralmente associado às altas temperaturas, porém, as baixas também devem ser consideradas. A velocidade do veículo de transporte eleva a ventilação e, consequentemente, as aves sentirão mais frio. O estresse pelo frio agrava-se quando as aves estão molhadas, fator comum em dias chuvosos. Nesses casos, há perda de temperatura pela evaporação da água. A recomendação para dias chuvosos é colocar uma proteção na parte superior da carga, e em temperaturas baixas não molhar as aves (Ribeiro, 2008).

Aumento da temperatura e umidade relativa do ar durante o transporte concatena para aumentos nos valores de temperatura retal e frequência respiratória, sendo que temperaturas em torno $46,3^{\circ} \mathrm{C}$ já se registram óbitos (Silva et al., 2007). 
O número de aves por caixa também é um fator agravante. Densidades elevadas (acima de sete aves por caixa), há um acréscimo na mortalidade no turno da tarde, seguido do turno da manhã e noite. Já nas densidades menores (abaixo de sete aves por caixa), a mortalidade foi elevada no turno da noite, seguida pelo turno da tarde e pelo turno da manhã, por causa do efeito da perda de calor sensível no turno da noite (Vieira, 2008).

O perfil microclimático da carga de caminhões de transporte é outro importante fator a ser considerado. As partes central e traseira da carga são os locais com a pior condição climática para o transporte. O turno da manhã geralmente é o horário mais propício para realizar essas operações por ser horário de temperaturas mais amenas (Barbosa Filho et al., 2009). Os fatores climáticos alterados do caminhão pode ser o principal motivo do comprometimento do bem-estar das aves e a qualidade final da carne com o desenvolvimento de PSE (Pale, Soft, Exudative) em filés de peito de frango (Simões et al., 2009).

A distância entre a granja e o abatedouro é de grande relevância em consideração às perdas pré-abate, já que ela determina a duração do transporte e o tempo em que as aves ficarão expostas aos efeitos térmicos do ambiente externo. Um estudo de Costa et al. (2007) compararam a distância entre o aviário e o abatedouro, com a posição das caixas na carga em relação ao número de aves lesionadas em duas integradoras. Nas distâncias maiores, o percentual de lesão foi maior, contudo independente da distância, houve uma maior incidência de lesão nas aves localizadas na parte traseira do veículo. Isso pode ser explicado pelos maiores efeitos de aceleração e vibração sofridos pelos animais situados neste local.

\subsubsection{Tempo de espera no abatedouro}

Após a chegada ao local de destino os caminhões de transporte aguardam em local geralmente coberto e aberto nas laterais, permitindo a ventilação, até o momento do abate. Essa etapa também deve ser bem planejada para não prejudicar o processo realizado previamente do bem-estar animal (Barbosa Filho, 2008). Reduzir a mortalidade (ou percentual de DOA "Dead on Arrivals") e garantir o bem-estar das aves de corte durante o último dia de vida implica em adequar logística e planejamento de cada caso.

Alguns galpões contêm climatizadores e nebulizadores como forma de amenizar o estresse térmico. Um estudo feito por Nääs et al. (1998) verificou eficiência nesse sistema, pois as gotículas de água lançadas pelos nebulizadores atingem as aves e com a ação do vento evaporam, retirando o calor excessivo, proporcionando-lhes uma melhor sensação térmica.

Quanto ao tempo de espera nos galpões, há resultados conflitantes, pois dependerá de vários fatores a ser analisado, tais como distância percorrida, clima da região, qual período do transporte e espera pré-abate, densidade das caixas, entre outros. De acordo com Ludtke et al. (2010) aves sob condições de estresse térmico não devem ser expostas a longos períodos de espera, pois eleva a mortalidade e pode causar danos à carcaça devido à desidratação, já que não recebem água ou ração no caminhão. O estudo recomenda o tempo máximo de duas horas. Já estudos de Vieira et al. (2011) concluíram que o tempo de espera de 3 a 4 horas num ambiente controlado durante o verão e primavera foi necessário para redução da carga térmica em frangos de corte. Um estudo anterior ainda avaliou os efeitos do tempo de espera no bem-estar e de mortalidade de frangos transportados em diferentes distâncias entre a granja e o abatedouro, concluindo que em distâncias acima de $25 \mathrm{~km}$, a mortalidade dos frangos foi menor quando adotado o tempo de espera curto, enquanto no mesmo intervalo de tempo para distâncias menores que 25 km, a mortalidade duplicou em relação à primeira situação (Vieira et al., 2010).

Evidências mostram uma menor concentração de corticosterona no plasma e diminuição da glicólise muscular em aves que tiveram tempo maior de espera no abatedouro após o transporte a longa distância (Zhang et al., 2009). O objetivo principal do descanso dos animais de abate é, além de atender o bem-estar animal, manter o caráter higiênico e conservação da carne a ser obtida (Brasil, 1952).

A Portaria $n^{\circ} 210$ (Brasil, 1998) solicita um local para recepção das aves com cobertura e ventilação, que pode ser 
usado para espera quando não for possível o abate imediato. Essa informação deixa espaço para múltiplas interpretações, contribuindo para a falta de padronização dessa etapa não menos importante na qualidade do produto final.

Os efeitos do estresse em aves são conhecidos, mas estudos específicos para avaliar de forma quantiqualitativa as perdas pré-abate, principalmente durante a fase de espera, se tornam cada vez mais necessários (Vieira et al., 2008).

\section{Parâmetros Hematológicos na Avicultura}

Exames laboratoriais sanguíneos são ferramentas importantes no auxílio de monitoramento da saúde, no diagnóstico de doenças e também para avaliação pré-operatória, tratamento e das condições de saúde das aves. Podem ser influenciados pelo estado nutricional, sexo, idade, habitat, estação do ano, estado reprodutivo, trauma, criação e estresse ambiental. A avaliação hematológica constitui-se em um ponto de partida para diagnóstico rápido e preciso que apresentam altos níveis zootécnicos na produção, relacionados também com a saúde destas aves. No Brasil, há poucos estudos nessa área, o que podem culminar interpretações erradas nos resultados obtidos (Schmidt et al., 2007).

Hematologia é a especialidade que estuda e trata doenças do sangue e de órgãos hematopoéticos, onde se formam as células do sangue e é composto pelas seguintes provas laboratoriais: eritrograma, leucograma e contagem de trombócitos (Schmidt et al., 2007).

O eritrograma é também conhecido como série vermelha, e as provas dessa linhagem são: contagem total de eritrócitos (também conhecidos como hemácias, ou ainda, glóbulos vermelhos), determinação do hematócrito, dosagem da hemoglobina e determinação dos índices hematimétricos (VGM, HGHM e CHGM). No leucograma (ou série branca) as provas são a contagem total de leucócitos (ou glóbulos brancos) e contagem leucocitária diferencial (Schmidt et al., 2007).

A contagem de trombócitos e pesquisa de hemoparasitas também podem ser realizadas, apesar de menos comum. Através de suas provas, é possível monitorar a saúde geral do animal, avaliando sua capacidade para transportar oxigênio e defender-se contra agentes parasitários (Voigt, 2003).

O profissional necessita conhecer a fisiologia das diferentes espécies e regiões para estabelecer prognóstico e protocolos terapêuticos para diferentes enfermidades com a ajuda de tais informações (Cordeiro, 2003). É um exame de diagnóstico rápido e preciso, porém limitado se utilizado sozinho (Rebar, 2003; Gonzáles \& Santos, 2005).

Todas as células do sistema sanguíneo das aves são nucleadas, caracterizando principal diferença entre aves e mamíferos. Mamíferos possuem eritrócitos e trombócitos anucleados. Tal diferença interfere nas contagens automatizadas. Outra característica diferencial é o principal leucócito da ave, o heterófilo, que se assemelha ao neutrófilo dos mamíferos. Deste modo, tais disparidades impedem o uso das contagens automatizadas utilizadas em amostras de mamíferos, sendo recomendadas as técnicas manuais (Capitelli \& Crosta, 2013).

Na contagem manual utiliza-se o hemocitômetro (câmara de Neubauer) sendo preenchido com a amostra diluída de sangue (Campbell, 1994). No Brasil, são comumente utilizados valores de referência do hemograma e bioquímica sanguíneos aqueles estabelecidos em outros países, onde o clima, região, nutrição e manejo diferem dos encontrados no país, gerando erros em interpretação dos resultados obtidos. Graças a esses fatos, há variações entre os valores médios e os limites superiores e inferiores relatados entre diversos autores (Borsa, 2009).

\subsection{Eritrograma}

Os eritrócitos são células ovais, nucleadas, com citoplasma eosinofílico e núcleo central redondo ou ovalado, com cromatina condensada, como mostra a Figura 4. É a célula mais encontrada em aves, e, assim como nos mamíferos, tem a função de transportar oxigênio para os tecidos (Haile \& Chanie, 2014). Possuem um tempo de vida mais curto comparado ao dos mamíferos, portanto a eritropoiese é mais intensa, sendo controlada pelos níveis de eritropoietina (produzida no rim) sob 
os estímulos de oxigênio sanguíneo e níveis de hormônios estrogênios e androgênios (Vila, 2013).

A contagem do número total é feita de modo manual, em câmara de Neubauer (ou hemocitômetro), diluindo parte da amostra com diluentes específicos contendo corantes. Logo após a coleta, faz-se também um esfregaço sanguíneo sem anticoagulante em lâmina para contagem diferencial das células (Campbell, 1994).

A determinação do hematócrito (volume de células compactadas) se faz através da técnica de microhematócrito. A concentração de hemoglobina é realizada com a mesma metodologia feita em amostras de mamíferos, utilizando análise espectrofotométrica com cianometahemoglobina a $540 \mathrm{~nm}$, porém a amostra deve passar por centrifugação após a lise dos eritrócitos para retirar os núcleos livres (Wakenell, 2010).

Os índices hematimétricos Volume Corpuscular Médio (VCM), Hemoglobina Corpuscular Média (HCM) e Concentração Média de Hemoglobina Corpuscular (CHCM) são calculados a partir dos valores totais de eritrócitos, hemoglobina e hematócrito. Avaliam, respectivamente, o tamanho dos eritrócitos e a quantidade média de hemoglobina por eritrócito (Campbell, 1994).

Valores referenciais de hematócrito em aves variam entre 35 a 55\%. Valores menores que 35\% são indicativos de anemia, e maiores que 55\% sugerem desidratação ou policitemia (Campbell,1994). Estudos de Schmidt et al. (2007) mostraram que esse parâmetro pode sofrer alteração em relação ao sexo e idade das aves.

Figura 4: Eritrócitos de aves. Notam-se diferentes maturações eritrocíticas.

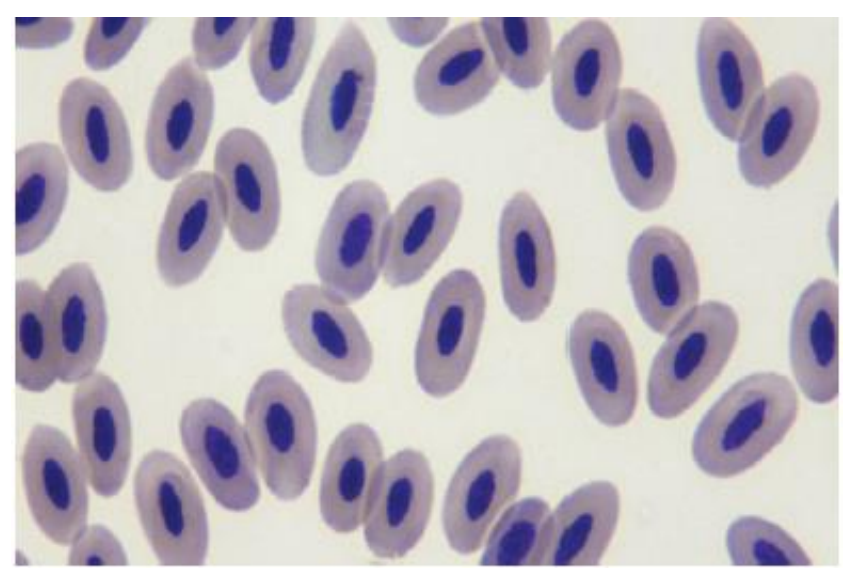

Fonte: Samour (2016)

\subsection{Leucograma}

A contagem total de leucócitos (WBC) é o ensaio de hematologia mais importante na avaliação de saúde e doença em animais. O WBC também é útil porque é usado em conjunto com a contagem diferencial de células brancas para calcular o número absoluto de cada glóbulo branco em uma amostra de sangue (Samour, 2005). O número total de leucócitos e a morfologia podem variar de acordo com a idade e sexo das aves (Schmidt et al., 2007). Essa contagem total é realizada junto com a contagem total de eritrócitos, e a contagem diferencial é feita no esfregaço sanguíneo sem anticoagulante, corado com corantes hematológicos (Romanowsky, Wright ou Wright Leishman) (Cândido, 2008).

Na contagem diferencial, devem ser diferenciados os heterófilos, eosinófilos, basófilos, monócitos e linfócitos. A avaliação dos trombócitos também é realizada no esfregaço (Cândido, 2008).

Os heterófilos são granulócitos que possuem funções semelhantes aos neutrófilos dos mamíferos, porém a forma como realizam essas funções são diferentes dos neutrófilos (Vila, 2013). São os principais fagócitos na primeira linha do sistema de defesa imunológico, o que indica que um aumento desse tipo celular (heterofilia) deve-se, primariamente, ao aumento da demanda para fagocitose (Samour, 2016). Sua morfologia é arredondada, com núcleo bi ou trilobulado e pocuo 
corado. O citoplasma é claro e com grânulos eosinófilos (Vila, 2013), como mostra a Figura 5.

Figura 5: Heterófilo bilobulado normal.

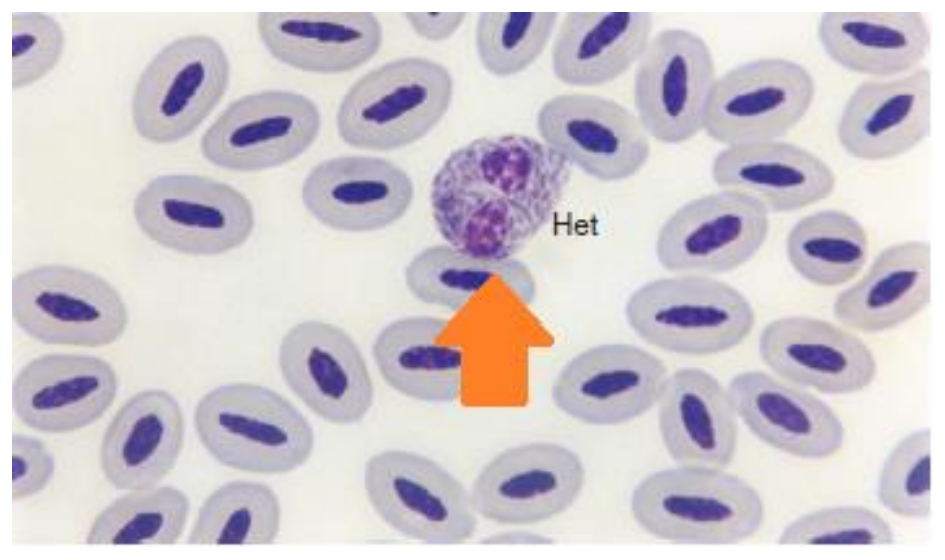

Fonte: Samour (2016).

Os eosinófilos são semelhantes aos heterófilos com o citoplasma mais basofílico, podendo ser difícil diferenciação entre um heterófilo (Figura 6). Seus grânulos eosinofílicos se coram com mais intensidade, o que caracterizam seu nome (Vila, 2013). São raros em espécies de aves, porém seu aumento está associado à presença de alguns parasitas e reações alérgicas (Haile \& Chain, 2014).

Figura 6: Eosinófilo e heterófilo em esfregaço periférico.

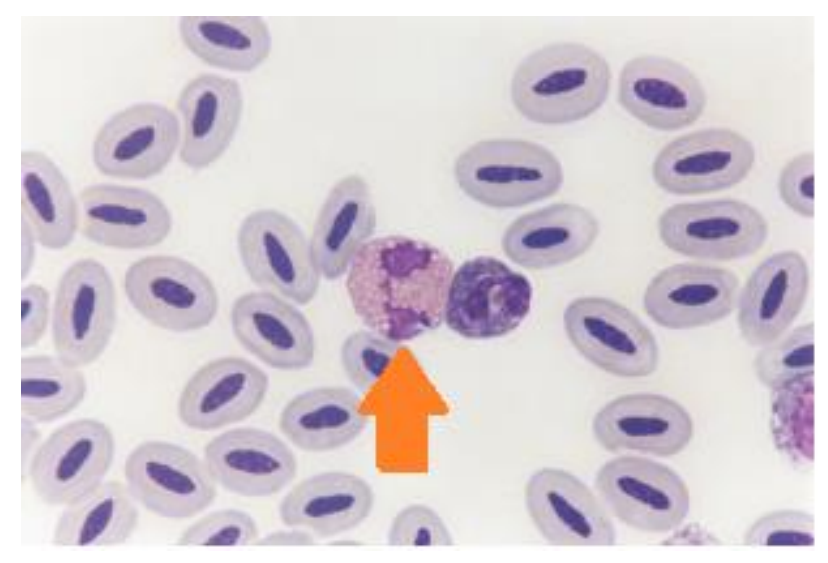

Fonte: Samour (2016)

O último granulócito a ser citado é o basófilo. Seus grânulos citoplasmáticos se coram intensamente de azul, o que pode dificultar a visualização do núcleo lobulado (Figura 7). Com função desconhecida, sugere-se estar envolvidos nas fases iniciais da inflamação aguda, mas essa condição não é frequente (Vila, 2013). 
Figura 7: Basófilo em esfregaço periférico.

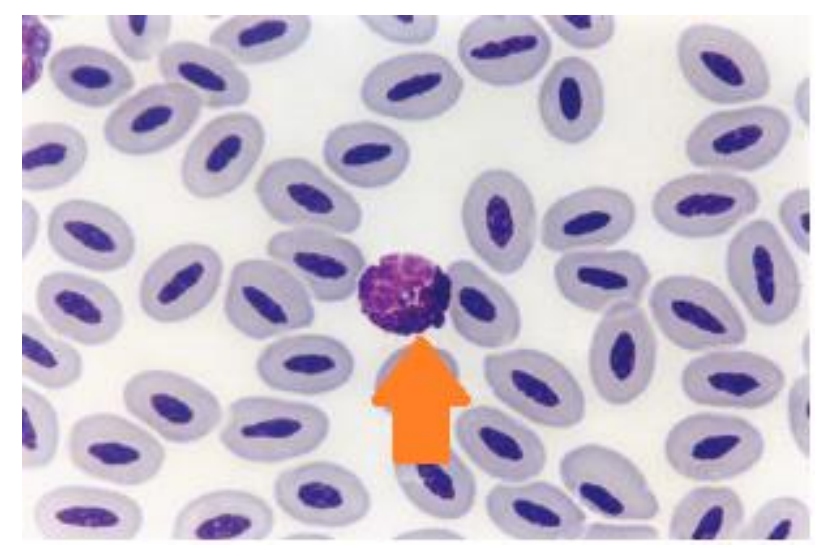

Fonte: Samour (2016).

Os linfócitos (Figura 8) são leucócitos menores, arredondados, com núcleo não lobulado de cor púrpura-escuro (Schmidt, 2007). O citoplasma é homogêneo e claro e a relação núcleo/citoplasma é alta (salvo exceções) (Vila, 2013). Exercem funções semelhantes aos linfócitos de mamíferos, atuando na imunidade celular (linfócitos T) e na imunidade humoral (linfócitos B) (Mitchel \& Johns, 2008). Os linfócitos representam a principal parte celular do sistema imunológico adquirido, que atua por meio de mecanismos antígenos-específicos. A estimulação recorrente com certo patógeno amplifica a escala e velocidade desta reação específica (Samour, 2016). O aumento deste tipo celular (linfocitose) está associado a estímulos antigênicos como em casos de infecções crônicas (independente do patógeno) ou neoplasia linfoide (Schmidt et al., 2007).

Figura 8: Linfócito em esfregaço sanguíneo.

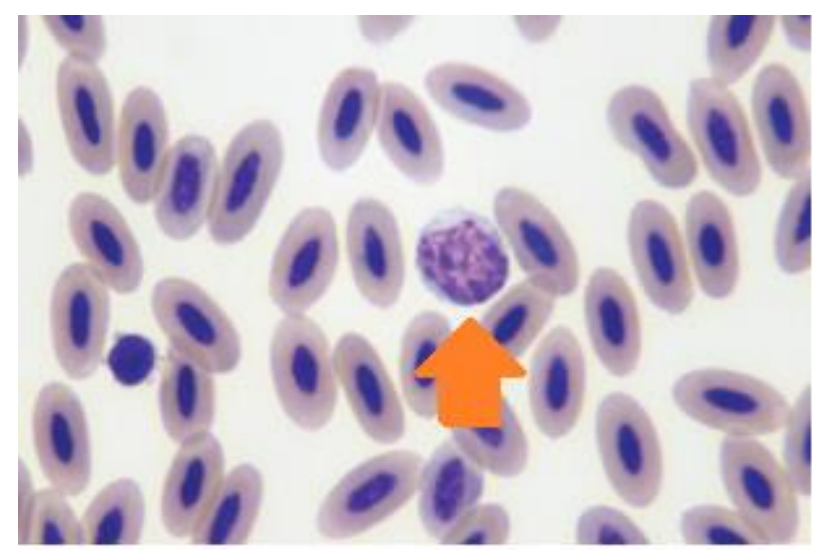

Fonte: Samour (2016).

Monócitos são células maiores que o linfócito, com mais citoplasma, de cor basofílica, e cromatina menos condensada. Pode ser vista de forma amorfa ou arredondada, com o núcleo redondo, oval ou lobulado (Figura 9) (Vila, 2013). Seu aumento está muitas vezes relacionado com doenças crônicas ou lesões granulomatosas fúngicas e bacterianas (Schmidt et al., 2007). 
Figura 9: Monócito em esfregaço sanguíneo.

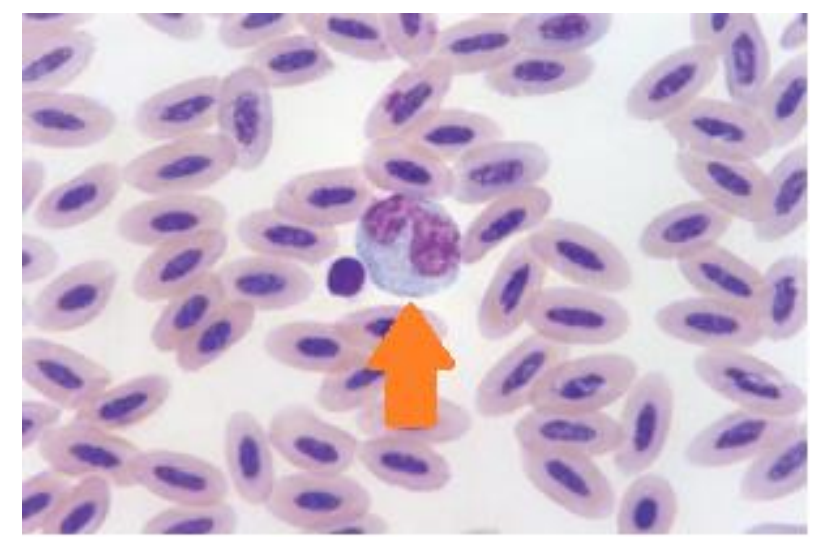

Fonte: Samour (2016).

Os trombócitos são pequenas células nucleadas, com pouco citoplasma (Figura 10). Pode ser facilmente confundido com um linfócito, porém seu tamanho é menor, com núcleo redondo e cromatina intensamente condensada (Vila, 2013). Participam da coagulação sanguínea e ocasionalmente participam nas funções de defesa do organismo (Schmidt et al., 2007).

Figura 10: Trombócitos em esfregaço sanguíneo.

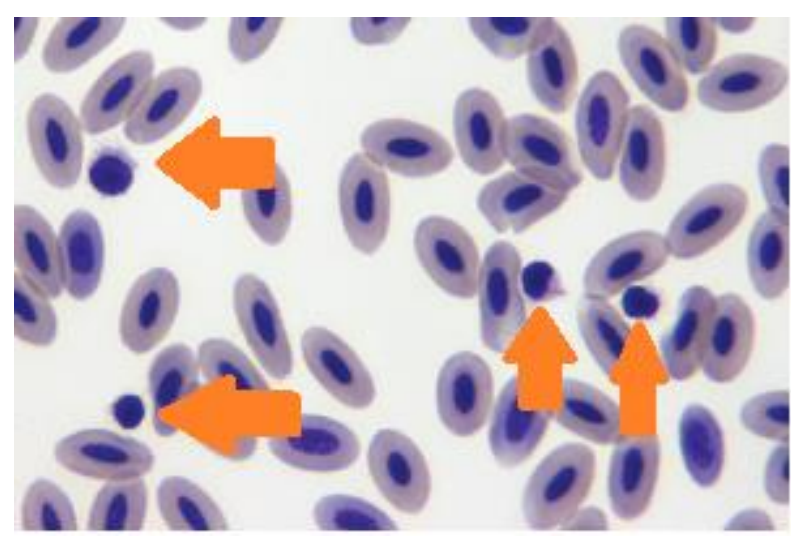

Fonte: Samour (2016).

\section{Hematologia do Estresse na Avicultura}

A alta sensibilidade do sistema sanguíneo às mudanças de temperatura o caracteriza em um importante indicador das respostas fisiológicas da ave a agentes estressores (Borges et al., 2003). O estresse calórico provoca redução nos pesos absoluto e relativo dos órgãos linfóides (Bursa e baço), redução na concentração de hemoglobina, variações nos valores de hematócrito, heterofilia e elevação na relação heterófilo/linfócitos (H/L) das aves. O peso relativo dos órgãos linfóides e a relação H/L mostram-se bons indicadores sanguíneos de estresse (Borges et al., 2003, Laganá et al., 2005).

A hematopoiese de aves em condições de estresse fica comprometida. Há aumento de eosinófilos e monócitos circulantes devido à leucopenia e linfopenia. Com a diminuição do número de linfócitos, o sistema imune se torna deficiente, deixando as aves suscetíveis às doenças (Marchini et al., 2011).

\section{Parâmetros Hormonais na Avicultura}

O sistema endócrino em aves inclui as glândulas tireoide, paratireoide, suprarrenais, último-braquiais, hipófise, pâncreas, pineal e gônadas. Os hormônios secretados pelas glândulas endócrinas são liberados diretamente na corrente 
sanguínea, atingindo todas as partes do corpo. São capazes de estimular ou inibir as funções de outros órgãos. Mesmo pequenas concentrações de um hormônio podem ter um profundo efeito nos processos corporais, influenciando ou causando mudanças patológicas em tecido muito distante de sua fonte (Saggese, 2016).

A maior parte do conhecimento do sistema endócrino aviário vem da galinha doméstica (Gallus gallus), e relatórios sobre distúrbios das glândulas endócrinas de outras aves continuam a ser limitadas a achados patológicos no exame pós-morte (Saggese, 2016).

Os animais homeotérmicos, como as aves, possuem no hipotálamo centros termorreguladores, que regulam a temperatura do corpo do animal, auxiliados por detectores de temperatura denominados termoreceptores. Estes termoreceptores transmitem impulsos dos neurônios para a medula, e através do hipotálamo, ocorre ativação hormonal e sistema nervoso autônomo (Navas et al., 2016).

\subsection{Glândulas tireoides}

As aves possuem duas glândulas tireoides, diferente dos mamíferos. Estes órgãos por sua vez têm como função influenciar a taxa de crescimento dos animais jovens e governar a taxa metabólica de todas as faixas etárias. Aumentam de tamanho quando há aumento na demanda, por exemplo, durante clima frio ou fase de postura de ovos. Liberam os hormônios triiodotironina (T3) e tetraiodotironina (T4 ou tiroxina), em resposta à liberação do hormônio tireotrófico (TSH), liberado pela hipófise. A secreção desses hormônios é influenciada pelo ciclo gonadal, clima/estação, estado de muda, fotoperíodo, entre outros. (Saggese, 2016).

A secreção dos hormônios tiroidianos acontece através de um ciclo de feedback negativo. Baixa concentração sanguínea de T3 estimula liberação de TSH pela hipófise, cessando tal liberação quando houver aumento de T3 circulante. A secreção de TSH é controlada pelo hipotálamo por meio da ação indireta do hormônio liberador de tireotrofina (TRH). O hipotálamo secreta TRH durante o estresse, hipotermia, doença febril e períodos de diminuição dos hormônios tireoidianos circulantes O TRH secretado pelo hipotálamo não é tireotrófico; em vez disso, aumenta a liberação do hormônio do crescimento (GH) pela glândula pituitária. O GH aumenta o T3, estimulando a monodeiodação de T4. Em aves, os hormônios da tireoide e os hormônios do crescimento estão relacionados pois os hormônios da tireoide inibem a síntese e liberação do hormônio do crescimento. O hormônio do crescimento parece prejudicar a liberação de T4 (Schmidt \& Reavill, 2008).

\subsection{Glândulas paratireoides}

As glândulas paratireoides ficam localizadas atrás das tireoides, e desempenham um importante papel no metabolismo do cálcio através da secreção do Hormônio da Paratireoide (PTH). O PTH aumenta os níveis de cálcio no sangue aumentando sua reabsorção tubular, óssea e gastrointestinal. Está presente na síntese da 1,25-OH-Vitamina D e na regulação de fósforo, diminuindo sua concentração através da excreção renal (Saggese, 2016).

O PTH é importante durante a postura dos ovos, quando muito cálcio é necessário, evitando que esse cálcio seja todo retirado da estrutura óssea e desempenha papel na contração dos músculos e coagulação sanguínea. Acredita-se que a paratireoide não esteja sob o controle de nenhum outro órgão endócrino, sendo estimulado pelo nível de cálcio no sangue. O nível de minerais no sangue de aves saudáveis é constante, mas em certas doenças pode cair acentuadamente e resultar no amolecimento dos ossos (Saggese, 2016). 


\subsection{Glândulas adrenais}

As glândulas adrenais são pequenas estruturas localizadas próximo aos rins. A principal função das células adrenocorticais aviárias é a produção de hormônios glicocorticoides e mineralocorticoides, como aldosterona e a corticosterona, sendo esta última, o hormônio corticoide mais importante produzido em aves adultas, diferente dos mamíferos, que secreta cerca de três a quatro vezes mais cortisol do que corticosterona (De Matos, 2008).

A corticosterona em aves é transportada no sangue ligada a duas proteínas plasmáticas específicas: globulina de ligação a corticosteroide (CBG) e albumina. A concentração dessas proteínas de transporte é influenciada por uma variedade de fatores como tiroxina, testosterona e hipofisectomia, todos os três diminuindo a concentração de CBG. O nível de corticosterona circulante é controlado em parte por sua ligação a essas proteínas, uma vez que, quando ligada, a disponibilidade da corticosterona para as células-alvo é reduzida e a depuração renal e hepática limitada (De Matos, 2008).

Estudos em codornas japonesas, pombos, galinhas, perus e patos mostraram um padrão diário distinto de concentrações sanguíneas de corticosterona circulantes. Em geral, as concentrações máximas são encontradas durante a noite ou na transição das fases claro-escuro (Carsia \& Harvey, 2000).

Os corticosteroides adrenais influenciam os processos metabólicos de quase todas as células do corpo e produzem diversos efeitos. Podem atuar diretamente nos tecidos-alvo ou serem modulados por interações com outros hormônios, incluindo hormônio tireoidiano, hormônio do crescimento, prolactina, norepinefrina e somatomedina C. Desempenha um papel importante na manutenção da homeostase, força muscular cardíaca e esquelética, atividade cerebral, regulação de eletrólitos e distribuição do compartimento de água, juntamente com o gerenciamento da resposta do organismo ao estresse. Os principais efeitos dos corticosteroides estão relacionados ao metabolismo, função imune, comportamento e equilíbrio eletrolítico (De Matos, 2008).

\subsection{Glândulas último-braquiais}

As glândulas último-braquiais são pequenas, e situadas próximo à origem das carótidas. Secretam a calcitonina, hormônio que também participa do metabolismo do cálcio (Saggese, 2016).

\subsection{Pâncreas}

O pâncreas aviário geralmente é composto de três lobos: dorsal, ventral e esplênico, com os lobos dorsal e ventral separados no pombo e no pato. Assim como nos mamíferos, possuem ação endócrina e exócrina. A porção endócrina do pâncreas ocupa consideravelmente mais massa de tecido do que em mamíferos e a distribuição dos tipos de células também difere. Existem três tipos de ilhotas descritas, que variam de acordo com a localização lobar e as espécies. Cada ilhota secreta um hormônio diferente. São eles: insulina, glucagon e somatostatina (Pilny, 2008).

O pâncreas exócrino fornece suco digestivo através dos dutos para ajudar na digestão do intestino delgado. A insulina aviária é um poderoso hormônio anabólico e muitas vezes mais potente do que a insulina dos mamíferos na estimulação da glicogênese e da hipoglicemia. O glucagon é um poderoso hormônio catabólico em aves e circula em níveis pelo menos oito vezes mais elevados do que em humanos. Os aumentos de glicose no sangue estimulam a liberação de insulina, e a diminuição dos níveis de glicose provoca a liberação de glucagon. Os receptores de glucagon aparecem em número muito maior do que os receptores de insulina em um determinado tecido, sugerindo que o glucagon é o hormônio dominante do metabolismo de carboidratos aviários (Pilny, 2008). 


\subsection{Glândulas sexuais}

A função reprodutiva de aves é controlada pelo eixo hipotálamo-hipófise-gonadal (HHG). Há a secreção de GnRH (hormônio liberador das gonadotrofinas) e peptídeo intestinal vasoativo (VIP) pelo hipotálamo que estimula a hipófise liberar os hormônios folículo-estimulante (FSH) e luteinizante (LH). Tais hormônios irão participar da liberação dos outros hormônios sexuais através da ativação nas glândulas sexuais, como prolactina, estradiol, progesterona e androgênicos com maiores concentrações nas fêmeas, e a testosteronas nos machos (De Figueiredo et al., 2021).

\subsection{Hipófise}

A hipófise, ou glândula pituitária é dividia em duas partes. A adenohipófise produz sete hormônios: o ACTH, que mantém atividade da glândula adrenal e controla a produção de corticosteroides adrenais, TSH, controla a atividade da tireoide e a secreção de hormônios tiroidianos. FSH e LH estimulam as gônadas em ambos os sexos, prolactina, ou hormônio lactogênico, suprime FSH e parece regular a deposição de gordura nas aves antes da migração. Há liberação ainda dos hormônios somatotrópicos ou os hormônios do crescimento que parecem regular o crescimento em pássaros imaturos e finalmente, a liberação do chamado hormônio estimulador dos melanócitos, cuja função não é claramente compreendido (Saggese, 2016).

A neurohipófise recebe e armazena dois hormônios, vasotocina e mesotocina. Vasotocina é um hormônio antidiurético que difere da vasopressina dos mamíferos por um resíduo de aminoácido. Sua principal ação em aves é inibir a perda de líquido dos rins, diminuindo a filtração glomerular. As outras ações conhecidas da vasotocina incluem o controle de reabsorção de água e estimulação dos movimentos peristálticos do oviduto durante a oviposição (Saggese, 2016).

\section{Alterações Hormonais no Estresse em Avicultura}

A consequência primária do estresse é uma alteração sobre a homeostase do animal. Caso o animal não consiga manter a homeostasia em algum momento, a consequência, mesma que rápida e esporádica, gera prejuízo ao bem estar animal (Broom \& Frasier, 2015). Ajustes fisiológicos, hormonais (T3 e T4) e moleculares ocorrem durante o estresse calórico (Lin et al., 2006).

O estresse inicialmente desencadeia uma resposta hormonal através da ativação do eixo hipotálamo-pituitária-adrenal (HPA). Há produção do hormônio liberador de corticotrofina (CRH), o qual estimula a glândula pituitária a aumentar a síntese de ACTH. Consequentemente, a glândula adrenal é estimulada a liberar glicocorticoides e catecolaminas que produzem lipólise, glicogenólise e catabolismo de proteínas. Estes hormônios mobilizam a produção e distribuição de substratos energéticos durante o estresse, e induzem alterações em várias funções do organismo que darão o suporte necessário para restabelecer a homeostase, assegurando a manutenção do organismo durante situações adversas. Quando essa ativação se torna crônica, passa a se tornar um perigo para o animal (Furlan et al., 2005).

O aumento de corticosteroide circulante causa diminuição do timo, da bursa de Fabricius e fígado, causando uma diminuição da produção de linfócitos, aumentando a razão heterófilo/linfócito, gerando imunidade deficiente (Hudelson \& Hudelson, 2005). Os corticosteroides podem atuar diretamente nos tecidos-alvo ou podem ser modulados por interações com outros hormônios, incluindo TSH, GH, prolactina, norepinefrina e somatomedina $\mathrm{C}$, participando de vários processos metabólicos, tais como aumento da gliconeogênese hepática, levando ao aumento de glicemia e insulina no sangue (casos crônicos de hiperinsulinemia pode levar a lipogênese, acarretando aumento da gordura corporal e levando à obesidade), reduz a síntese proteica, levando à perda de massa muscular. Os corticosteroides também interferem no sistema imunológico e no balanço eletrolítico (De Matos, 2008). 
Diversos estudos realizados mostram alterações em níveis de corticosteroides e parâmetros bioquímicos durante as diversas etapas do pré-abate (Nidjam et al., 2005; Bedanova et al., 2007; Vosmerova et al., 2012). No Quadro 1, algumas causas de elevação de corticosteroides são citadas.

Quadro 1 - Causas de elevação de corticosteroides.

\begin{tabular}{|c|}
\hline Elevação de corticosterona \\
\hline - Imobilização \\
\hline - Restrição de proteínas \\
\hline - Inanição \\
\hline - Medo \\
\hline - Dor \\
\hline - Aumento da osmolalidade plasmática \\
\hline • Oviposição \\
\hline - Prostaglandinas \\
\hline - Baixo 3,5,3'-triiodotironina (T3) \\
\hline - Metabolismo hepático deprimido de \\
\hline corticosterona \\
\hline - Hormônio do crescimento \\
\hline - Angiotensina II (Ver Fig. 19.8) \\
\hline - Prolactina \\
\hline - Hormônio da paratireóide (PTH) \\
\hline - Catecolaminas \\
\hline - Serotonina \\
\hline - Peptídeo intestinal vasoativo \\
\hline - Células imunológicas ativadas \\
\hline - Fator de liberação de corticotropina \\
\hline - Arginina vasotocina \\
\hline - Mesotocina \\
\hline - Hormônio adrenocorticotropina (ACTH) \\
\hline - Melatonina \\
\hline - Progesterona \\
\hline - Exercício \\
\hline
\end{tabular}

Fonte: Adaptado de Hudelson e Hudelson (2005).

Os hormônios tiroidianos também sofrem alterações quando expostos a luz ou mudança climática. Galinhas jovens e adultas secretam metade da taxa de T4 no verão comparado ao inverno. Este efeito está diretamente relacionado à temperatura ambiente. No inverno, as células foliculares são mais colunares e o volume folicular é maior. Durante o dia, há diminuição de T4 enquanto T3 é elevado, ocorrendo processo inverso no período da noite. A ingestão de alimentos e a composição da dieta também estão relacionadas à concentração e ao metabolismo do hormônio tireoidiano. A relação T4 / T3 aumenta durante o jejum e a concentração plasmática de TSH diminui (Schmidt \& Reavill, 2008). 
Os hormônios tiroidianos exercem a regulação da temperatura corporal das aves. Há diminuição da concentração de T3 quando em altas temperaturas, e as concentrações de T4 são menos consistentes. A redução da atividade reprodutiva das aves pode ser devido à depleção do funcionamento da tireoide (Mack et al., 2013).

Manter as aves longe de luz solar por muito tempo também pode causar estresse e prejudicar o metabolismo do cálcio. A falta de exposição à luz UVB pode afetar a biodisponibilidade do cálcio devido à diminuição da produção de vitamina D3 (De Matos, 2008).

Em relação ao sistema sexual, estudos relataram menores pesos dos ovários e ovidutos em poedeiras comerciais criadas com dietas com baixo índice proteico e elevadas temperaturas, além de redução no número de folículos grandes. Demonstram diminuição dos níveis de hormônios esteroides (progesterona e testosterona), além de redução de LH, provavelmente devido ao aumento de níveis de prolactina (Novero et al., 1991, Bunchasak \& Silapasom, 2005). Os glicocorticoides diminuem a concentração de GnRH no hipotálamo, importante regulador de FSH e LH , resultando na inibição do comportamento sexual e redução da produtividade (Carvalho, 2020).

Há aumento da susceptibilidade a doenças oportunistas quando as aves são expostas a aumento de temperatura, pois ocorrem modificações na fisiologia e na estrutura das células, assim como na função e na estrutura das membranas celulares, deixando os frangos mais debilitados, causando a queda do sistema imune (Cassuce, 2011). A suplementação de rações com vitamina $\mathrm{C}$ em associação com cromo pode promover aumento dos níveis de T3 e T4 circulantes, além da redução de corticosterona (Sahin et al., 2002), gerando efeitos positivos no metabolismo e no consumo de ração, melhorando o desempenho de aves mantidas sob estresse por calor.

\section{Perspectivas Futuras}

O estresse por calor em aves sempre será tema de discussão no Brasil devido às altas temperaturas. Tal estresse causa grande prejuízo na avicultura, elevando os custos da produção com equipamentos e instalações, além de proporcionar alta mortalidade. Assim, os efeitos negativos oriundos de temperaturas elevadas podem ser amenizados, estudando o animal em relação a sua fisiologia, comportamento e o ambiente que ele vive, tentando manter o bem-estar aliado ao aumento da produção.

Para que isso ocorra, os testes hematológicos e hormonais podem constituir-se no elo entre produção e bem estar das aves. Os testes hematológicos, hormonais e testes de estimulação estão mais disponíveis à medida que muitas universidades e laboratórios de diagnóstico veterinário começaram a fornecem tais serviços. Porém, muitos testes ainda precisam ser validados para a diversidade de tipos de aves.

\section{Conclusão}

O estresse térmico e fases pré-abate de aves podem gerar diversas alterações metabólicas que são detectadas com análises clínicas hormonais e hematológicas. Estas análises visam preparar e disponibilizar os recursos necessários para o organismo enfrentar as demandas emergenciais compensatórias, visando à manutenção e homeostase do organismo para melhorias nas condições oferecidas ao bem estar animal nesta fase. Estes exames são importantes para elucidar lacunas de conhecimento e contribuir para minimizar os efeitos adversos que a fisiologia do estresse traz à avicultura moderna.

\section{Referências}

ABPA - Associação Brasileira de proteína Animal. (2021). Mercados - Aves. https://abpa-br.org/mercados/

Albino, L. F. T. Carvalho, B. R. Maia, R. C. \& Barros, V. R. S. M. (2014). Galinhas Poedeiras: Criação e Alimentação. Aprenda Fácil. 376p. 
Barbosa Filho, J. A. D. Vieira, F. M. C. Silva, I. J. Garcia, D. B. (2009). Transporte de frangos: caracterização do microclima na carga durante o inverno. Revista Brasileira de Zootecnia, 38(12), 2442-2446. https://doi.org/10.1590/S1516-35982009001200021

Barbosa Filho, J. A. D. (2008). Caracterização quantiqualitativa das condições bioclimáticas e produtivas nas operações pré-abate de frangos de corte. Tese de Doutorado, Escola Superior de Agricultura Luiz de Queiroz, Universidade de São Paulo, Piracicaba. http://doi:10.11606/T.11.2008.tde-17072008-153053

Bedanova, I. Voslarova, E. Chloupek, P. Pistekova, V. Suchy, P. Blahova, J. \& Vecerek, V. (2007). Stress in broilers resulting from shackling. Poultry Science, 86(6), 1065-1069. http://doi.org/10.1093/ps/86.6.1065

Borges, S. A., Maiorka, A.; Silva, A. V. F. (2003). Fisiologia do estresse calórico e a utilização de eletrólitos em frangos de corte. Ciência Rural, 33(5), pp. 975-981. http://doi.org/10.1590/S0103-84782003000500028

Borsa, A. (2009). Valores hematológicos em frangos de corte de criação industrial. Colloquium Agrariae, 5(1), 25 - 31. https://doi.org/10.5747/ca.2009

Brasil. Ministério da Agricultura, Pecuária e Abastecimento. (2000). Instrução normativa n.3 . https://www.gov.br/agricultura/ptbr/assuntos/sustentabilidade/bem-estar-animal/arquivos/arquivos-legislacao/in-03-de-2000.pdf

Brasil. Ministério da Agricultura, Pecuária e Abastecimento. (1998). Portaria Nº 210, de 10 de novembro de 1998. Diário Oficial da União. Brasília, DF. Seção 1, p.226. https://www.agencia.cnptia.embrapa.br/Repositorio/Portaria-210_000h19kjcan02wx7ha0e2uuw60rmjy11.pdf

Brasil. Ministério da Agricultura, Pecuária e Abastecimento. (1952). Regulamento de Inspeção Industrial e Sanitária de Produtos de Origem Animal, Decreto 30.691 de 29/03/1952. https://www2.camara.leg.br/legin/fed/decret/1950-1959/decreto-30691-29-marco-1952-339586-normaatualizada-pe.pdf

Broom, D. M. \& Fraser, A. F. (2015) Domestic animal behaviour and welfare.: Cabi.

Brossi, C. Contreras-Castillo, C. J. Amazonas, E. D. A. \& Menten, J. F. M. (2009). Estresse térmico durante o pré-abate em frangos de corte. Ciência Rural, 39, 1284-1293. http://doi.org/10.1590/S0103-84782009005000039

Bunchasak C. \& Silpasorn T. (2005). Effects of adding methionine in low protein diet on production performance, reproductive organs and chemical liver composition of laying hens under tropical conditions. International Journal of Poultry Sciences, 4, 301- 308. http://doi.org/10.3923/ijps.2005.301.308

Campbell, T. W. (1994). Hematology. In: Ritchie, B. W. Harrison, G. J. Harrison L. R. Avian medicine: principles and application. (pp.176-198). Lake Worth: Wingers Publishing.

Cândido, M. V. (2008). Hematologia, bioquímica sérica e nutrição em aves: Cracidae. Universidade Federal do Paraná, Curitiba. http://hdl. handle. net/1884/16089

Capitelli, R. Crosta, L. (2013). Overview of psittacine blood analysis and comparative retrospective study of clinical diagnosis, hematology and blood chemistry in selected psittacine species. Veterinary Clinics of North America: Exotic Animal Practice, 16, 71-120.

Carrasco, G. A. \& Van De Kar, L. D. (2003). Neuroendocrine pharmacology of stress. European Journal of Pharmacology, 463,235-272. http://doi.org/ $10.1016 /$ S0014-2999(03)01285-8

Carsia, R.V. \& Harvey, S. (2000). Sturkie's avian physiology. Wittow.

Carvalho, T. (2020). Estresse térmico em poedeiras: definição do estresse e consequências fisiológicas. Revista Agroceres Multimix. https://agroceresmultimix.com.br/blog/estresse-termico-em-poedeiras-definicao-do-estresse-e-consequencias-fisiologicas/

Cassuce, D. C. (2011). Determinação das faixas de conforto térmico para frangos de corte de diferentes idades criados no Brasil. Universidade Federal de Viçosa, Viçosa. http://locus.ufv.br/handle/123456789/752

CEC - Commission of the European Communities. (2005). Laying down minimum rules for protection of chickens kept for meat production. Bruxelas: European Union. https://eur-lex.europa.eu/legal-content/EN/TXT/PDF/?uri=CELEX:32007L0043\&qid=1637925305613\&from=en

Cordeiro P. H. C. (2003). Fragmentação da Mata Atlântica no Sul da Bahia e suas implicações na conservação dos psitacídeos. In: Prado P.I., Landau E.C., Moura R.T., Pinto L.P.S., Fonseca G.A.B., Alger K.N. Corredor de Biodiversidade da Mata Atlântica do Sul da Bahia. Ilhéus: IESB/CI/CABS/UFMG/Unicamp. https://ibama.angelfire.com/papagaios.pdf

Costa, F. M. Prata, L. F., \& Pereira, G. T. (2007). Influência das condições de pré-abate na incidência de contusões em frangos de corte. Revista Veterinária e Zootecnia, 14(2), 234-245. https://doi.org/10.34188/bjaerv3n3-058

De Figueiredo, E. M. Corrêa, G. S. S. Albino, L. F. T. Donzele, R. F. M. O. Donzele, J. L. Pinto, R., Da , M. D. Corrêa, A. B. \& Tavares, J. M. N (2021). Inovações na Nutrição Animal desafios da produção de qualidade. Editora Científica Digital. Cap 8, p 109-126. http://doi.org/10.37885/210504516

De Matos, R. (2008). Adrenal steroid metabolism in birds: anatomy, physiology, and clinical considerations. Vet Clin North Am Exot Anim Pract ,17, 35-57. https://doi.org/10.1016/j.cvex.2007.09.006

DEFRA- Department for Environment, Food and Rural Affairs. (2007) The welfare of poultry and slaugther or killing. London https://assets.publishing.service.gov.uk/government/uploads/system/uploads/attachment_data/file/485659/pb13539-welfare-poultry-slaughter.pdf

Duangjinda, M. Tunim, S. Duangdaen, C. \& Boonkum, W. (2017). Hsp70 genotypes and heat tolerance of commercial and native chickens reared in hot and humid conditions. Brazilian Journal of Poultry Science, 19 (1), 7-18. https://doi.org/10.1590/1806-9061-2016-0245

Ebeid, T. A. Suzuki, T. \& Sugiyama, T. (2012). High temperature influences eggshell quality and calbindin-D28k localization of eggshell gland and all intestinal segments of laying hens. Poultry Science. 91, 2282-2287. https://doi.org/10.3382/ps.2011-01898 
Ebrahimzadeh, S. K. Farhoomand, P. \& Noori, K. (2012). Immune response of broiler chickens fed diets supplemented with different level of chromium methionine under heat stress conditions. Asian-Australas. J. Anim. Sci., 25, 256. http://dx.doi.org/10.5713/ajas.2011.11217

El-Kholy, M. S. El-Hindawy, M. M. Alagawany, M. ABD El-Hack, M. E. ABD EL, S. A. E. G. \& EL-Sayed, H. (2017). Dietary supplementation of chromium can alleviate negative impacts of heat stress on performance, carcass yield, and some blood hematology and chemistry indices of growing Japanese quail. Biological trace element research, 179(1), 148-157. http://doi.org/10.1007/s12011-017-0936-Z

Encarnação, R. O. (1992). Estresse e produção animal. Empresa Brasileira de Pesquisa Agropecuária -EMBRAPA Campo Grande, MS. http://docsagencia.cnptia.embrapa.br/bovinodecorte/doc/doc34/doc34.pdf

Furlan, R. L. Macari, M. \& Mateus, J. R. (2005) Bem-estar das aves e suas implicações sobre o desenvolvimento e produção. Fórum Internacional de Avicultura, 1, 60-68. https://pt.engormix.com/avicultura/artigos/bem-estar-aves-desenvolvimento-e-producao-t36653.htm

Garcia, R. G. Almeida Paz, I. C. L. Caldara, F. R. Näs̈s, I. A. Pereira, D. F. \& Ferreira, V. M. O. S. (2012). Selecting the most adequate bedding material for broiler production in Brazil. Brazilian Journal of Poultry Science, 14(2), 121-127. http://doi.org/10.1590/S1516-635X2012000200006

Gonzalez, F. H. D. \& Santos, A. P. (2005). Patologia Clínica Veterinária. In: II Simpósio de Patologia Clínica Veterinária da Região Sul do Brasil, Porto Alegre. Anais... Porto Alegre. https://www.ufrgs.br/lacvet/site/wp-content/uploads/2013/05/II_simp_patol_clin2005.pdf

Gobi, J. P. (2020). Equilíbrio ácido-básico em aves - importância e estratégias para manutenção. Polinutri. https://polinutri.com.br/upload/artigo/259_p.pdf

Haile, Y. \& Chanie, M. (2014). Comparative aspects of the clinical hematology of birds: a review. British Journal of Poultry Sciences, 3(3), 88-95. https://doi.org/10.5829/idosi.bjps.2014.3.3.83263

Hudelson, K. S. \& Hudelson, P. M. (2005). Endocrine Considerations. In: Harrison, G. J. Lightfoot, T. L. Clinical Avian Medicine: Vol II (. p 541-578 ). Spix Publishing, Inc

Laganá, C. Ribeiro, A. M. L. Gonzalez, F. H. D. Lacerda, L. A. Terra, S. R. \& Barbosa, P. R. (2005). Suplementação de vitaminas e minerais orgânicos nos parâmetros bioquímicos e hematológicos de frangos de corte em estresse por calor. Boletim de Indústria Animal,62(2), 157-165. http://www.iz.sp.gov.br/bia/index.php/bia/article/view/1307.

Lin, H. Jiao, C. H. Buyse. J. \& Decuypere, E. (2006). Strategies for preventing heat stress in poultry. Poultry Science, 62, 71-95. https://doi.org/10.1079/WPS200585

Ludtke, C. B. Ciocca, J. R. P. Dandin, T. Barbalho, P. C. \& Vilela, J. A. (2010). Abate humanitário de aves. WSPA Brasil, Rio de Janeiro https://www.pubvet.com.br/uploads/ac07140915d3eb1a45169aa674eca72f.pdf

Macari, M. Furlan, R. L. \& Gonzales, E. (2002) Fisiologia aviária aplicada a frangos de corte. Campinas: FACTA https://www.researchgate.net/publication/284150771_Fisiologia_aviaria_aplicada_a_frangos_de_corte

Mack, L. A. Felver-Gant, J. N. Dennis, R. L. \& Cheng, H. W. (2013). Genetic variation alter production and behavioral responses following heat stress in 2 strains of laying hens. Poultry Science. 92, 285-294. https://doi.org/10.3382/ps.2012-02589

Marchini, C. F. P. Nascimento, M. R. B. M. \& Silva, P. L. Guimarães, E. C. (2011). Parâmetros hematológicos de frangos de corte submetidos à temperatura ambiente cíclica $\quad$ elevada. In XXII $\quad$ Latin American $\quad$ Poultry https://www.researchgate.net/publication/247151681_Parametros_hematologicos_de_frangos_de_corte_submetidos_a_temperatura_ambiente_ciclica_elevada

Mehaisen, G. M. Ibrahim, R. M. Desoky, A. A. Safaa, H. M. El-Sayed, O. A. \& Abass, A. O. (2017). The importance of propolis in alleviating the negative physiological effects of heat stress in quail chicks. Plos One, 12(10), e0186907. https://doi.org/10.1371/journal.pone.0186907

Mitchell, E. B. \& Johns, J. (2008). Avian hematology and related disorders. Veterinary Clinics of North America: Exotic Animal Practice, 11(3), 501-522. https://doi.org/10.1016/j.cvex.2008.03.004

Mitchell, M. A. \& Kettlewell, P. J. (2009). Welfare of poultry during transport - a review. Poultry Welfare Symposium Cervia, 18-22. https://www.researchgate.net/publication/255627668_Welfare_of_poultry_during_transport_-_A_review

Nääs, I. A. Silva, I. J. O. \& Gouveia, R. P. (1998). Avaliação de sistemas de resfriamento no ambiente de espera em caixas transportadoras de frango de corte utilizando a ventilação e nebulização. Revista de Engenharia Rural, 9: 50. https://pt.engormix.com/avicultura/artigos/avaliacao-estresse-termico-condicaot38397.htm

Navas, T. O. De Oliveira, H. F. De Carvalho, F. B. Stringhini, J. H. Café, M. B. \& Hellmeister Filho, P. (2016). Estresse por calor na produção de frangos de corte. Nutritime Revista Eletrônica,13(1), p.4550-4557. Viçosa. https://www.nutritime.com.br/arquivos_internos/artigos/361_-_4550-4557_-_NRE_13-1_janfev_2016.pdf

Nijdam E. Delezie E. Lambooij E. Nabuurs M.J. Decuypere E. \& Stegeman J. A. (2005). Comparison of bruises and mortality, stress parameters, and meat quality in manually and mechanically caught broilers Poultry Science; 84(3):467-74. https://doi.org/10.1093/ps/84.3.467

Nijdam E. Arens P. Lambooij E. Decuypere E. \& Stegeman J. A. (2004). Factors influencing bruises and mortality of broilers during catching, transport, and lairage. Poult Sci.; 83(9):1610-5. http://doi.org/10.1093/ps/83.9.1610

Novero, R. P. Beck, M. M. Gleaves, E. W. Johnson, A. L. \& Deshazer J. A. (1991). Plasma progesterone, luteinizing hormone concentrations, and granulosa cell responsiveness in heat-stressed hens. Poultry Science. 70:2335-2339. https://doi.org/10.3382/ps.0702335

Pilecco, M. Paz, I. C. D. L. A. Tabaldi, L. A. Nääs, I. Garcia R. G. Caldara, F. R. \& Cavichiolo, F. (2011). Influência de fatores genéticos, ambientais e de manejo sobre a incidência de arranhões dorsais em frangos de corte. Agrarian, 4(14), 352-358. http://doi.org/10.30612/agrarian.v4i14.1268 
Pilny, A. A. (2008): The avian pancreas in health and disease, Vet Clin North Am Exot Anim Pract 11:25-34. https://doi.org/10.1016/j.cvex.2007.09.007

Porto, M. L. \& Fontenele-Neto, J. D. (2020). Efeito da manipulação térmica durante a incubação sobre as variáveis hematológicas, bioquímica sérica e morfometria da bolsa cloacal de codornas japonesas submetidas ao estresse crônico por calor. Arquivo Brasileiro de Medicina Veterinária e Zootecnia, 72, 505-516. http://doi.org/10.1590/1678-4162-11132

Prodanov, C. C \& Freitas, E. C. (2013). Metodologia do trabalho científico: métodos e técnicas de pesquisa e do trabalho acadêmico. (2ª edição, 276p). Novo Hamburgo-RS: Feevale.

Rebar, A. H. (2003). Guia de Hematologia para cães e gatos. Editora Roca Ltda, São Paulo, p. 291. ISBN 857241441X

Ribeiro, C. S. (2008). Bem-animal como pré-requisito de qualidade na produção de frangos de corte. 47f. Universidade Castelo Branco, RJ. https://bdm.unb.br/handle/10483/17987

Rodrigues, D. R. Café, M. B. Jardim Filho, R. M. Oliveira, E. Trentin, T. C. Minafra, C. S. (2017).Metabolismo de frangos de corte submetidos a diferentes tempos de espera no abatedouro e sua relação com a qualidade da carne. Arquivo Brasileiro de Medicina Veterinária e Zootecnia, 69 (3). https://doi.org/10.1590/1678-4162-9268

Rui, B. R. Angrimani, D. S. R \& Alves Da Silva, M. A. (2011). Pontos críticos no manejo pré-abate de frango de corte: jejum, captura, carregamento, transporte e tempo de espera no abatedouro. Ciência Rural, 41(7),1290-1296. https://doi.org/10.1590/S0103-84782011005000092

Schmidt, E. M. S. Locatelli-Dittrich, R. Santin, E., \& Paulillo, A. C. (2007). Patologia clínica em aves de produção-uma ferramenta para monitorar a sanidade avícola-revisão. Archives Of Veterinary Science, 12(3). http://dx.doi.org/10.5380/avs.v12i3.10906

Saggese, M. D. (2016). Disorders of the Endocrin System. In: Samour, J. Avian Medicin. (p 408-416). Abu Dhabi. Elsevier.

Sahin, K. Sahin, N. \& Kucuk, O. (2003). Effects of chromium, and ascorbic acid supplementation on growth, carcass traits, serum metabolites, and antioxidant status of broiler chickens reared at a high ambient temperature $\left(32^{\circ} \mathrm{C}\right)$. Nutrition Research, 23(2), 225-238. https://doi.org/10.1016/S0271-5317(02)00513-4

Samour, J. (2016). Avian Medicine.3th edition. ((p74-178). Abu Dhabi . Elsevier.

Samour, J. (2005). Diagnostic Value of Hematolgy. In: Harrison, G. J. Lightfoot, T. L. Clinical Avian Medicine: Vol II (p 587-610). Spix Publishing, Inc.

Schmidt, E. M. S. Paulillo, A. C. Santin, E. Dittrich, R. L. \& De Oliveira, E. G. (2007). Hematological and serum chemistry values for the ring-necked pheasant (Phasianus colchicus): variation with sex and age. Int. J. Poultry Science, 6, 137-139. http://dx.doi.org/10.3923/ijps.2007.137.139

Schmidt R. E., Reavill, D. R. (2008): The avian thyroid gland, Vet Clin North Am Exot Anim Pract 11:15-23. https://doi.org/10.1016/j.cvex.2007.09.008

Silva, J. H.V. Jordão Filho, J. Costa, F.G.P. Lacerda, P. B.D. Vargas, D. G. V. Lima, M. R. (2012). Exigências nutricionais de codornas. Revista Brasileira de Saúde e Produção Animal, 13, 775-790. https://www.scielo.br/j/rbspa/a/kJDrRVLb6cMr7p6hskmZKzj/?lang=pt\#: :text=Codornas\%2 0exigem\%20mais\%20prote\%C3\%ADna\%20(amino\%C3\%A1cidos,mesma\%20propor\%C3\%A7\%C3\%A3o\%20que\%20os\%20frangos.

Silva, I.J. O. \& Vieira, F. M. C. (2010) Ambiência animal e as perdas produtivas no manejo pré-abate: o caso da avicultura de corte brasileira. Archivos de Zootecnia, 59 (232), 113-131. https://doi.org/10.21071/az.v59i232.4910

Silva, M. A. N. Barbosa Filho, J. A. D. Silva, C. J. M. Rosário, M. F. Silva, I. Coelho, A. \& Savino, V. (2007). Avaliação do estresse térmico em condição simulada de transporte de frangos de corte. Revista Brasileira de Zootecnia. 36. https://doi.org/10.1590/S1516-35982007000500020

Simões, G. S. Oba, A. Matsuo, T. Rossa, A. Shimokomaki, M. \& Ida, E. I. (2009). Vehicle thermal microclimate evaluation during Brazilian summer broiler transport and the occurrence of PSE (Pale, Soft, Exudative) meat. Brazilian Archives of Biology and Technology, 52, 195-204. https://doi.org/10.1590/S151689132009000700025

UBA, União Brasileira de Avicultura. (2008). Protocolo de bem-estar para frangos e perus. https://edisciplinas.usp.br/pluginfile.php/4314928/mod_folder/content//Protocolo\%20de\%20Bem-Estar\%20Frangos\%20e\%20Perus.pdf?forcedownload=1

Vieira, F. M. C. (2008). Avaliação das perdas e dos fatores bioclimáticos atuantes na condição de espera pré-abate de frangos de corte. Escola Superior de Agricultura Luiz de Queiroz, Universidade de São Paulo, Piracicaba. https://doi.org/10.11606/D.11.2008.tde-25072008-121656

Vieira, F. M. C. Silva, I. J. O. Barbosa Filho, J. A. D. Vieira, A. M. C. \& Broom, D. M. (2011). Preslaughter mortality of broilers in relation to lairage and season in a subtropical climate. Poultry Science, 90, 2127-2133. https://doi.org/10.3382/ps.2010-01170

Vieira, F. M. C. Silva, I. J. O. Barbosa Filho, J. A. D. \& Vieira, A. M. C. (2012). Redução das perdas pré-abate de frangos de corte: efeito da densidade de aves submetidas aos diferentes tempos de espera no abatedouro. Journal of Animal Behaviour and Biometeorology. 1. 1-6

Vila, L.G. (2013). Hematologia em aves: revisão de literatura. Escola de Veterinária e Zootecnia da Universidade Federal de Goiás - UFG. Goiânia. https://www.passeidireto.com/arquivo/67549945/hematologia-em-aves-revisao-de-literatura

Vogado, G. M. S. Vogado, K. T. S. Fonseca, W. J. L Fonseca, W. L. Vogado, W. F. Oliveira, A. M. Oliveira, N. M. \& Luiz, C. S. M (2016). Evolução da Avicultura Brasileira. Nucleus Animalium, 8(1). Ituverava. https://dialnet.unirioja.es/servlet/articulo?codigo=5760014

Voigt G. L. (2003). Conceptos y Técnicas Hematológicas para Técnicos Veterinários. Acribia, Zaragoza. p. 144.

Vosmerova, P. Chloupek,J. Bedanova, I. Chloupek,P. Kruzikova, K. Blahova, J. \& Vecerek, V.(2010). Changes in selected biochemical indices related to transport of broilers to slaughterhouse under different ambient temperatures, Poultry Science, 89(12), 2719-2725. https://doi.org/10.3382/ps.2010-00709

Wakenell, P. S. (2010). Hematology of chicken and turkey. In: D. S. Weiss K. J. Wardrop, (eds): Schalm's veterinary hematology. 6th ed ( pp: 958-966) 
Research, Society and Development, v. 11, n. 3, e16111326303, 2022

(CC BY 4.0) | ISSN 2525-3409 | DOI: http://dx.doi.org/10.33448/rsd-v11i3.26303

Blackwell Publishing.

WSPA, Sociedade Mundial de Proteção Animal. Abate Humanitário. 2017. https://www.gov.br/agricultura/pt-br/assuntos/producao-animal/arquivospublicacoes-bem-estar-animal/programa-steps-abate-humanitario-de-aves.pdf/@ @download/file/programa-steps-abate-humanitario-de-aves.pdf

Zambello, A. V. Soares, A. G. Tauil, C. E. Donzelli, C. A. Fontana, F. \& Chotolli, W. P. (2018). Metodologia da pesquisa e do trabalho científico. (1 ${ }^{a}$ ed., 94p). Organizador: Thiago Mazucato Penápolis-SP: FUNEPE.

Zhang, L. Yue, H. Y. Zhang, H. J. Xu, L. Wu, S. G. Yan, H. J. Gong, Y. S. \& Qi, G. H. (2009). Transport stress in broilers: I. Blood metabolism, glycolytic potential, and meat quality. Poultry Science, 88, 2033-2041. https://doi.org/10.3382/ps.2009-00128 